\title{
Calcined sodium silicate as an efficient and benign heterogeneous catalyst for the transesterification of natural lecithin to L- $\alpha$-glycerophosphocholine
}

https://doi.org/10.1515/gps-2017-0190

Received January 17, 2018; accepted January 17, 2018; previously published online February 21, 2018

Abstract: Calcined sodium silicate could serve as an efficient and benign heterogeneous catalyst for the production of L- $\alpha$-glycerophosphocholine from natural lecithin. The catalytic transesterification of natural lecithin by calcined sodium silicate proceeded to almost $100 \%$ conversion under the following conditions: sodium silicate amount of $6 \mathrm{wt} \%$, reaction temperature of $65^{\circ} \mathrm{C}$, lecithin concentration of $10.5 \mathrm{mmol} / \mathrm{l}$, stirring intensity of $300 \mathrm{rpm}$, reaction time of $120 \mathrm{~min}$. In addition, this catalyst could be separated completely by simple centrifugation and retained high activity after three re-uses. Compared to the previously reported catalysts, calcined sodium silicate, with the significantly important characteristics of non-toxicity and easy excretion from the human body, was beneficial to the benign production of L- $\alpha$-glycerophosphocholine and its security as well as application in food and medicine fields.

Keywords: benign catalyst; heterogeneous catalysis; L- $\alpha$ glycerophosphocholine; sodium silicate.

\section{Introduction}

L- $\alpha$-glycerophosphocholine (GPC) as a phospholipid metabolite can be used in pharmaceuticals field [1, 2]. In addition, some researches have demonstrated that GPC has positive effects on attention, memory, cognition, brain or mental disease [3-5]. As a functional food and medicine, the most suitable preparation method is the transesterification

*Corresponding author: Xiaoli Zhang, School of Chemical Engineering, Northwest University, Xi'an, Shaanxi 710069, China, e-mail: xlzhang@nwu.edu.cn

Bin Li, Pengjuan Fan, Lei Liu, Binglin Li, Wenbo Dong and

Binxia Zhao: School of Chemical Engineering, Northwest University, Xi'an, Shaanxi 710069, China

Hongya Li: School of Chemistry and Chemical Engineering, Yulin University, Yulin, Shaanxi, China

Dopen Access. (cc)BY (C) 2019 Walter de Gruyter GmbH, Berlin/Boston of natural lecithin [6-10]. However, only limited literatures have reported the transesterification of natural lecithin. In the early stage, homogeneous catalysts such as mercuric chloride [11], tetrabutylammonium hydroxide [12], and sodium methoxide [13] have been used to catalyze the transesterification of lecithin to prepare GPC. The serious drawback of this process is the catalyst residue in the prepared GPC, which can affect its security and usage [14].

Therefore, many investigations have paid attention to developing the novel process, in which there is no residue of toxic components, or the catalyst can be easily separated and recycled. For example, the low boiling point organic amines, quaternary ammonium resin has been used to catalyze the transesterification of lecithin, respectively. The main benefit of this process is that the catalyst can be easily separated by distillation [10] or simple centrifugation [15]. In spite of the remarkable advance, the resulting GPC may be contaminated by the toxic catalyst. Hence, there is still much scope for the development of a benign heterogeneous catalyst to achieve the aim of preparing GPC with a benign process.

Sodium silicate as an organic salt is non-toxic [16]. In addition, sodium silicate taken orally can be easily absorbed from the alimentary canal and excreted in urine [16]. These significant characteristics indicate that sodium silicate can serve as a suitable catalyst for the production of GPC. Therefore, we have reported herein the production of GPC from natural lecithin with the friendly calcined sodium silicate. The effects of reaction temperature, stirring intensity, lecithin concentration, and catalyst amount were investigated in detail. In addition, the recyclability of sodium silicate and the catalyst residue in reaction solution were also tested.

\section{Materials and methods}

\subsection{Materials}

Sodium metasilicate $\left(\mathrm{Na}_{2} \mathrm{SiO}_{3} \cdot 9 \mathrm{H}_{2} \mathrm{O}\right)$ used in this study was purchased from Kermel Chemistry Co. Ltd. (Tianjin, China). Soybean lecithin (90\% phospholipids) was obtained from Sigma-Aldrich Corp. (St. Louis, MO, USA). All other reagents were of standard laboratory grade. 


\subsection{Catalyst preparation and characterization}

In order to determine the calcination temperature region, $\mathrm{Na}_{2} \mathrm{SiO}_{3} \cdot 9 \mathrm{H}_{2} \mathrm{O}$ was analyzed by thermogravimetric analysis-derivative thermogravimetric (TG-DTG), which was performed on a thermogravimetric analyzer (STA449F3, NETZSCH, Germany) under nitrogen flow with a heating rate of $10 \mathrm{~K} / \mathrm{min}$ from room temperature to $800^{\circ} \mathrm{C}$. To prepare the catalyst, $\mathrm{Na}_{2} \mathrm{SiO}_{3} \cdot 9 \mathrm{H}_{2} \mathrm{O}$ was calcined in an oven at the optimal temperature for $2 \mathrm{~h}$. Then, the resulting catalyst was triturated and passed through a 120-mesh sieve.

The base strength and basicity of the catalysts calcined at different temperatures were determined by the Hammett indicator and Hammett indicator-benzene carboxylic acid titration methods $[17,18]$. First, the base strength distribution was measured by the color changes of indicators adsorbed on sodium silicate. Then, the basicity of different alkali strengths was measured by the titration of methanol solution of benzene carboxylic acid (Kermel Chemistry Co. Ltd. Tianjin, China). In addition, the total basicity was the sum of all different base strength contents. X-ray diffraction (XRD) spectra were recorded on a powder XRD instrument (D8 ADVANCE, Bruker, Germany). Scanning electron microscopy images were detected on a scanning electron microscope (Sigma 500, Carl Zeiss, Germany). Fourier transform infrared spectroscopy (FT-IR) was performed using a Fourier transform infrared spectrometer (Frontier, PerkinElmer, USA). The fresh, recycled catalyst was dissolved in hydrofluoric acid and analyzed by an inductively coupled plasma (ICP) spectrometer (Optima 7000 DV, PerkinElmer, USA).

\subsection{Transesterification process}

Phospholipid (PC) was dissolved in methanol and the solution was introduced to a $150 \mathrm{ml}$ three-necked flask equipped with a reflux condenser. The calcined sodium silicate was added to react for $120 \mathrm{~min}$. The reaction mixture ( $20 \mu \mathrm{l}$, approximately $15 \mathrm{mg})$ was periodically withdrawn and centrifuged at $4000 \mathrm{rpm}$ for $1 \mathrm{~min}$. Some $10 \mu \mathrm{l}$ of the upper liquid were taken to analyze the amount of PC reacted.

\subsection{High performance liquid chromatography analysis}

The PC in the reaction mixture were analyzed by high performance liquid chromatography (LC-20A, Shimadzu, Japan) equipped with an evaporative light-scattering detector (Chromachem, ESA, USA) under the reported testing condition [19]. The conversion of PC was calculated as the ratio of the difference between the initial mass of $\mathrm{PC}$ and that after reaction to the initial mass of PC.

\section{Results and discussion}

\subsection{Catalyst characterization}

As seen in Figure 1, the weight loss of sodium metasilicate was divided into two stages. The main weight loss (about $50 \%$ ) range of room temperature to $170^{\circ} \mathrm{C}$ was

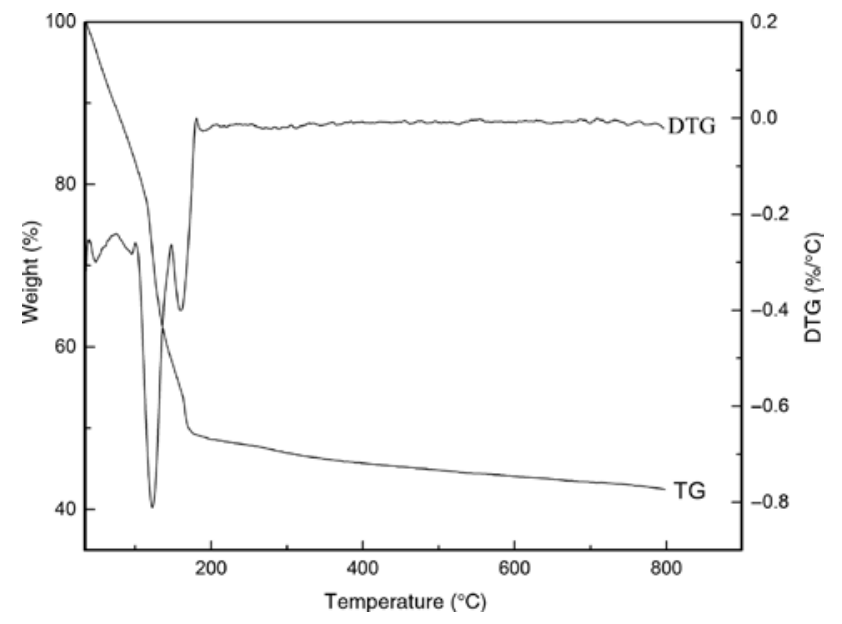

Figure 1: TG/DTG curves of sodium metasilicate.

ascribed to the desorption of adsorbed water [20] and the loss of bound water [21]. Less than $10 \%$ weight loss was observed in the $170-800^{\circ} \mathrm{C}$ region, which was likely attributed to the loss of water trapped in the framework [20]. By contrast, no DTG peak appeared at the second weight loss region, which showed that the high temperature calcination would not result in decomposition, crystallization and melting of sodium silicate [20]. In view of these results, the bound water was removed in the low temperature region; therefore, the range of $170-800^{\circ} \mathrm{C}$ was chosen to investigate the optimal calcination temperature. In addition, the sodium metasilicate was calcined at $200^{\circ} \mathrm{C}$, $300^{\circ} \mathrm{C}, 400^{\circ} \mathrm{C}$ and $500^{\circ} \mathrm{C}$.

The base strength distribution and basicity of sodium silicate calcined at different temperatures are summarized in Table 1 . The total basicity first increased and then decreased with increasing calcination temperature. The result was similar to that obtained by Xie et al. [17]. With the calcination temperature of $300^{\circ} \mathrm{C}$, the highest total basicity of $12.96 \mathrm{mmol} / \mathrm{g}$ was obtained. However, the optimum catalyst was obtained at $400^{\circ} \mathrm{C}$, which possessed the highest strong base content $\left(\mathrm{H}_{0}=15.0-18.4\right)$. Correspondingly, the highest PC conversion of $98.7 \%$ was obtained in the presence of this catalyst. This result was in agreement with that obtained from other reactions catalyzed by calcined sodium silicate $[21,22]$. Therefore, the optimal calcination temperature was $400^{\circ} \mathrm{C}$.

The XRD diffraction patterns of $\mathrm{Na}_{2} \mathrm{SiO}_{3} \cdot 9 \mathrm{H}_{2} \mathrm{O}$ and calcined sodium silicate are shown in Figure 2. The non-calcined sample was assigned to $\mathrm{Na}_{2} \mathrm{SiO}_{3}$ with nine molecules of bound water (JCPDS No. 16-0815) and the crystalline phase was the orthorhombic phase [22]. After calcination treatment, the intensity of some diffraction 
Table 1: Basicity distribution of sodium silicate calcined at different temperature.

\begin{tabular}{|c|c|c|c|c|c|}
\hline \multirow[t]{2}{*}{ Temperature } & \multicolumn{4}{|c|}{ Basicity of different basic strength ranges $(\mathrm{mmol} / \mathrm{g})$} & \multirow[t]{2}{*}{ Conversion (\%) } \\
\hline & $H_{0}=7.2-9.8$ & $H_{0}=9.8-15.0$ & $H_{0}=15.0-18.4$ & Total basicity & \\
\hline $200^{\circ} \mathrm{C}$ & 1.95 & 8.12 & 0.43 & 10.51 & 69.4 \\
\hline $300^{\circ} \mathrm{C}$ & 2.84 & 9.22 & 1.04 & 12.96 & 79.6 \\
\hline $400^{\circ} \mathrm{C}$ & 4.19 & 6.58 & 1.59 & 12.34 & 98.7 \\
\hline $500^{\circ} \mathrm{C}$ & 4.00 & 6.40 & 1.20 & 11.61 & 94.4 \\
\hline
\end{tabular}

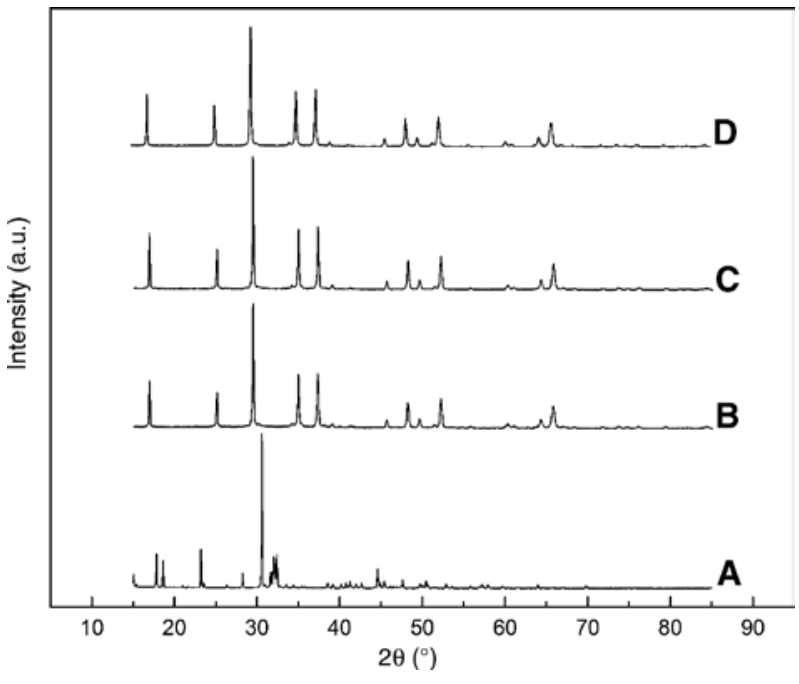

Figure 2: X-ray diffraction (XRD) patterns of (A) sodium metasilicate, (B) $200^{\circ} \mathrm{C}$, (C) $400^{\circ} \mathrm{C}$, and (D) $500^{\circ} \mathrm{C}$.

peaks at $2 \theta$ angles of $16.79^{\circ}, 25.05^{\circ}, 34.93^{\circ}, 37.22^{\circ}, 48.16^{\circ}$, $52^{\circ}$ and $65.65^{\circ}$ (JCPDS No. 16-0818) increased, which suggested that the crystalline phase of $\mathrm{Na}_{2} \mathrm{SiO}_{3}$ was the hexagonal phase [22]. By contrast, no change in crystalline phases of the catalysts calcined at different temperatures was observed. However, the crystallite size of the catalyst calcined at $400^{\circ} \mathrm{C}(\mathrm{D}=58.14 \mathrm{~nm}$, calculated by Jade 6.0$)$ was larger than that at $200^{\circ} \mathrm{C}(\mathrm{D}=20.28 \mathrm{~nm})$ and $500^{\circ} \mathrm{C}$ $(\mathrm{D}=30.61 \mathrm{~nm})$. Correspondingly, the catalyst calcined at $400^{\circ} \mathrm{C}$ possessed the highest strong basic center content. Therefore, we speculated that the large crystallite size crystallization had a positive effect on the formation of strong alkali centers.

The morphologies of the samples before and after calcination are shown in Figure 3. The sodium metasilicate surface was smooth and continuous. After being calcined at $400^{\circ} \mathrm{C}$, a large number of particles loosely aggregated at the catalyst surface forming many interstices. These interstices could act as channels to readily facilitate the diffusion of PC/GPC molecules to/from the active base site in the internal surface. Therefore, the sodium silicate performed with higher activity after calcination.
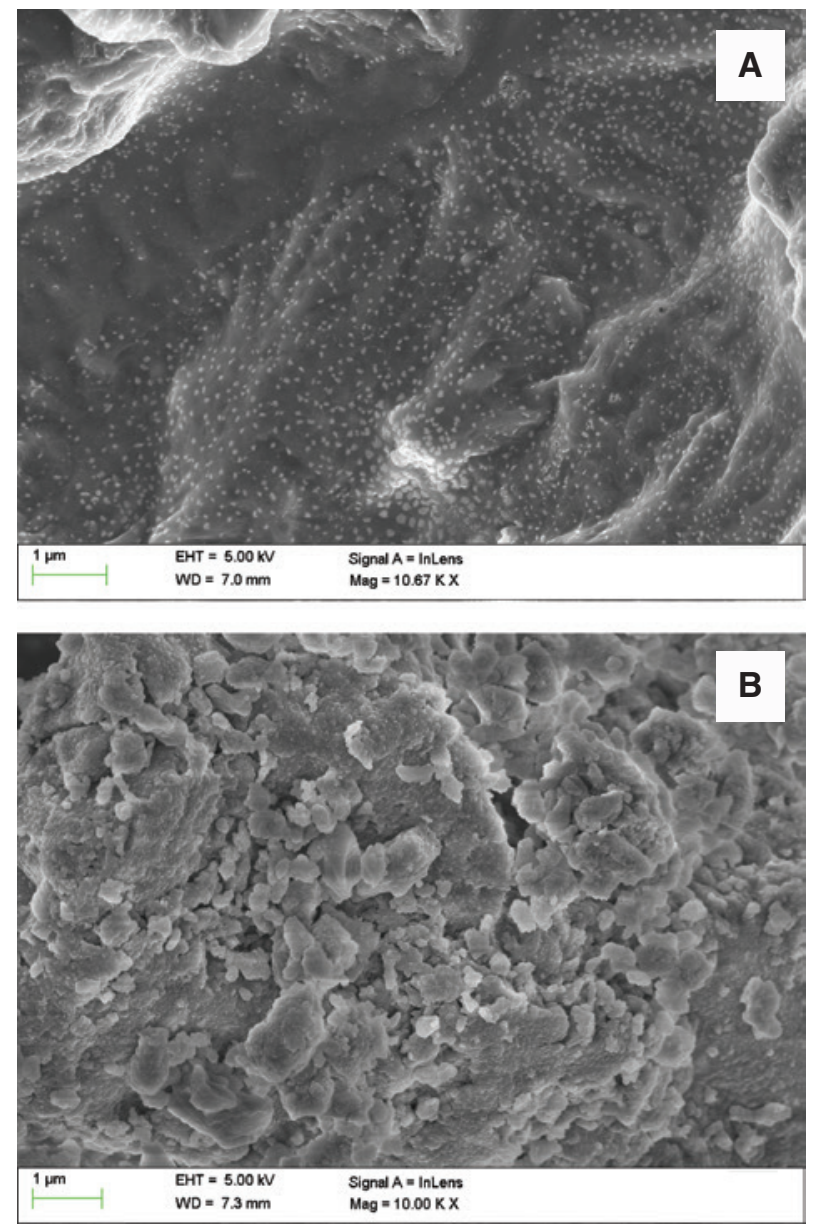

Figure 3: Scanning electron microscopy (SEM) images of (A) sodium metasilicate, (B) sodium silicate calcined at $400^{\circ} \mathrm{C}$.

The FT-IR spectra of $\mathrm{Na}_{2} \mathrm{SiO}_{3} \cdot 9 \mathrm{H}_{2} \mathrm{O}$ and calcined sodium silicate are shown in Figure 4. IR bands at about $3300 \mathrm{~cm}^{-1}$ and $1600 \mathrm{~cm}^{-1}$ were observed, which were assigned to the hydroxyl groups of adsorbed and bound water [23]. The bands at $849 \mathrm{~cm}^{-1}$ and $880 \mathrm{~cm}^{-1}$ were ascribed to the different forms of the stretching vibration of O-Si-O [21, 24]. After calcination, the bands at about $3300 \mathrm{~cm}^{-1}$ and $1600 \mathrm{~cm}^{-1}$ disappeared, demonstrating that the adsorbed and bound water were removed. 


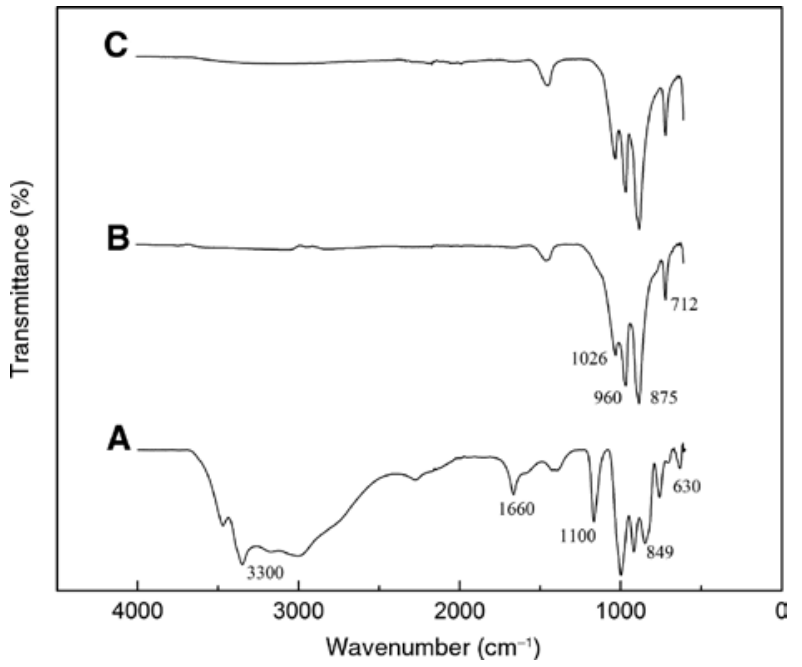

Figure 4: Fourier transform infrared spectroscopy (FT-IR) spectra of (A) sodium metasilicate, (B) sodium silicate calcined at $400^{\circ} \mathrm{C}$, and (C) recycled sodium silicate.

The disappearance of the peaks at about $1100 \mathrm{~cm}^{-1}$ and $630 \mathrm{~cm}^{-1}$ was likely due to the change in tetrahedral $\mathrm{SiO}_{4}^{4-}$. New Si-O-Si stretching bands appeared at about $710 \mathrm{~cm}^{-1}$ and $880 \mathrm{~cm}^{-1}$, which were attributed to the aggregation of tetrahedral $\mathrm{SiO}_{4}^{4-}$ and hence formed $\mathrm{Si}-\mathrm{O}-\mathrm{Si}$ [22]. The formed Si-O-Si was beneficial in increasing the mechanical strength [25]. In addition, the depolymerization of formed Si-O-Si (water $>3 \%$ ) and the gelation of sodium silicate (water $>20 \%$ ) [26] could be circumvented under anhydrous conditions. Therefore, the calcined sodium silicate could maintain high stability. Meanwhile, the intensity of $\mathrm{Si}-\mathrm{O}-\mathrm{Na}$ stretching vibration at about $1000 \mathrm{~cm}^{-1}$ [21] became weak. An explanation for this result was that the part of sodium ion was wrapped in the crystal interior [22].

\subsection{Effects of transesterification parameters}

The effect of stirring intensity on the transesterification of $\mathrm{PC}$ is shown in Figure 5. The PC conversion increased from $55 \%$ to $82 \%$ after $60 \mathrm{~min}$ with increase in the stirring intensity from $100 \mathrm{rpm}$ to $300 \mathrm{rpm}$. The increase in reaction rate was probably due to the acceleration of mass transport of PC molecules from solution to particle surface. However, with a further increase in stirring intensity, no appreciable enhancement was observed in the conversion of PC. This phenomenon likely illustrates that the acceleration of diffusion came up to a maximum. Considering the PC conversion and economy aspect, the optimum stirring intensity was chosen as $300 \mathrm{rpm}$.

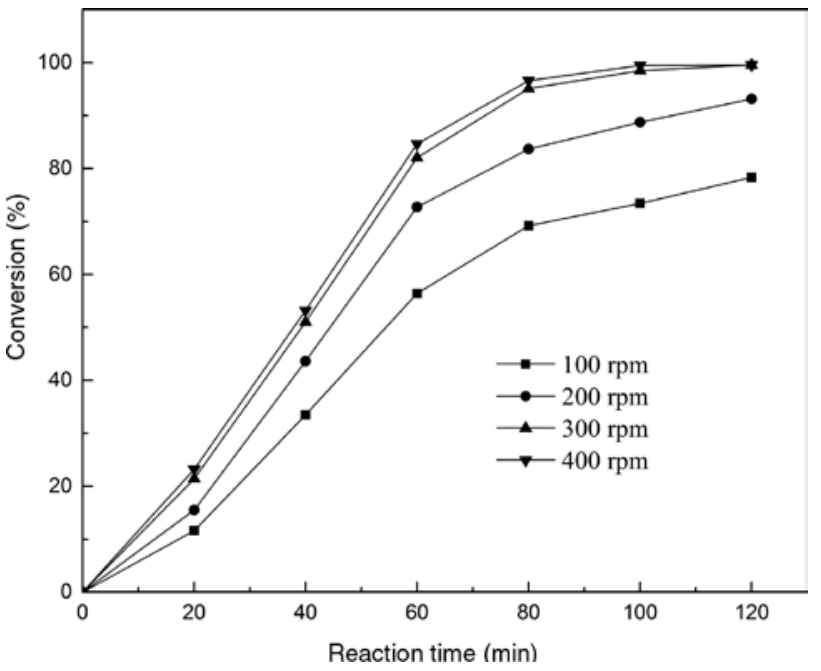

Figure 5: The effect of stirring intensity on catalytic transesterification of phospholipid (PC) by calcined sodium silicate.

The effect of different temperatures on the reaction was investigated. As seen in Figure 6, reaction temperature had a positive effect on the transesterification process. Raising the temperature from $55^{\circ} \mathrm{C}$ to $65^{\circ} \mathrm{C}$ resulted in the increase in PC conversion from $89 \%$ to about $100 \%$. This was probably because elevating the temperature contributed to the miscibility and reactivity between the reactants [27]. When temperature was raised to $70^{\circ} \mathrm{C}$, only slight enhancement was observed in the PC conversion compared to that at $65^{\circ} \mathrm{C}$. This result was similar to that obtained by other researchers [28-30]. An explanation for this phenomenon was that the gasification of methanol could reduce the reactants concentration and hinder

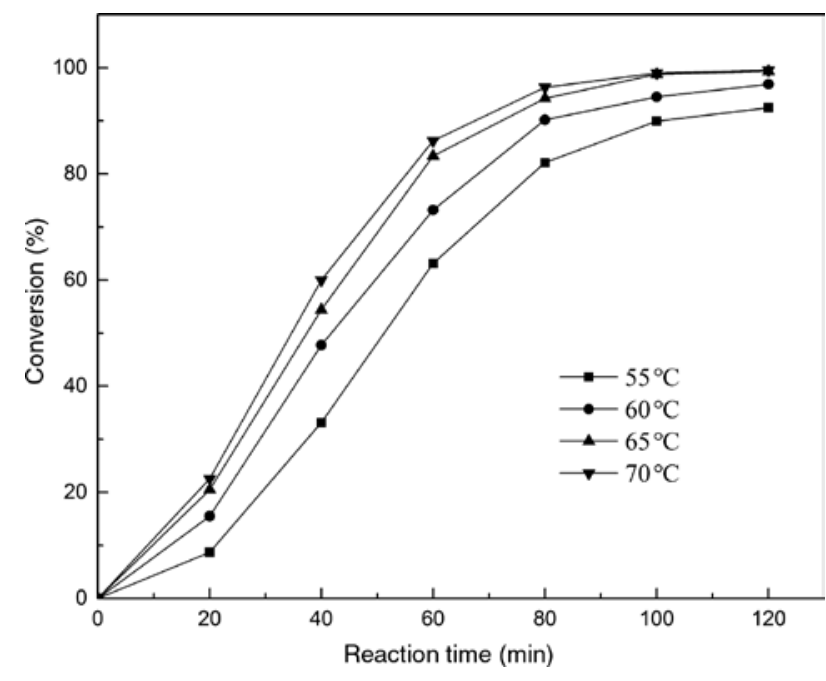

Figure 6: The effect of reaction temperature on transesterification of phospholipid (PC). 


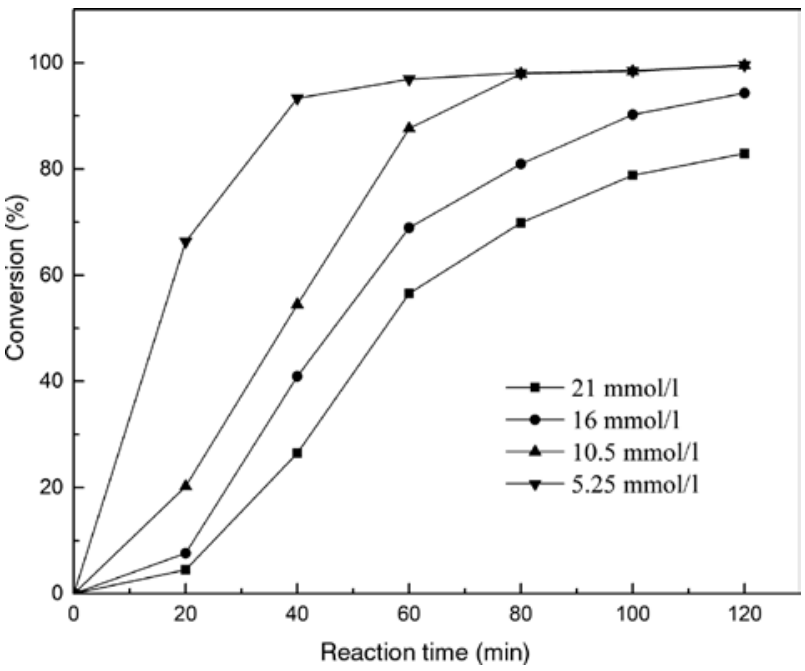

Figure 7: The effect of phospholipid (PC) concentration on transesterification of PC catalyzed by calcined sodium silicate.

the transesterification [31, 32]. In view of these results, a temperature of $65^{\circ} \mathrm{C}$ was selected as the optimal reaction temperature.

The effect of PC concentration on reaction was investigated, which is shown in Figure 7. It can be observed that increasing the PC concentration from $5.25 \mathrm{mmol} / \mathrm{l}$ to $10.5 \mathrm{mmol} / \mathrm{l}$ led to the enhancement in PC conversion. However, a sharp decrease in PC conversion was observed with a further increase in the $\mathrm{PC}$ concentration to $21 \mathrm{mmol} / \mathrm{l}$. The single PC molecules could interact with each other to form large-size aggregates with increase in the concentration [33] and, as a result, the interfacial area between PC and sodium silicate could reduce, resulting in the decrease in reaction rate [34]. Considering the PC conversion and reaction rate, $10.5 \mathrm{mmol} / \mathrm{l} \mathrm{PC}$ concentration was chosen as the optimum concentration.

The effect of different catalyst amounts from $4 \mathrm{wt} \%$ to $7 \mathrm{wt} \%$ on the transesterification is shown in Figure 8. The reaction rate was observed to increase with the increase in catalyst amount. As expected, PC conversion clearly increased from $62 \%$ to $93 \%$ after 80 min with increasing the catalyst amount from $4 \mathrm{wt} \%$ to $6 \mathrm{wt} \%$. The easier availability of the catalytic active centers was largely responsible for the enhancement in reaction rate and this result was in accordance with the fact that the transesterification rate increased with increasing the number of active sites [35]. However, with a further addition of the catalyst, only slight acceleration of reaction rate was observed compared to that using $6 \mathrm{wt} \%$. This was likely due to the shielding effect of catalyst particles on stirring [36]. In this context, the catalyst amount of $6 \mathrm{wt} \%$ was chosen as the optimization of transesterification.

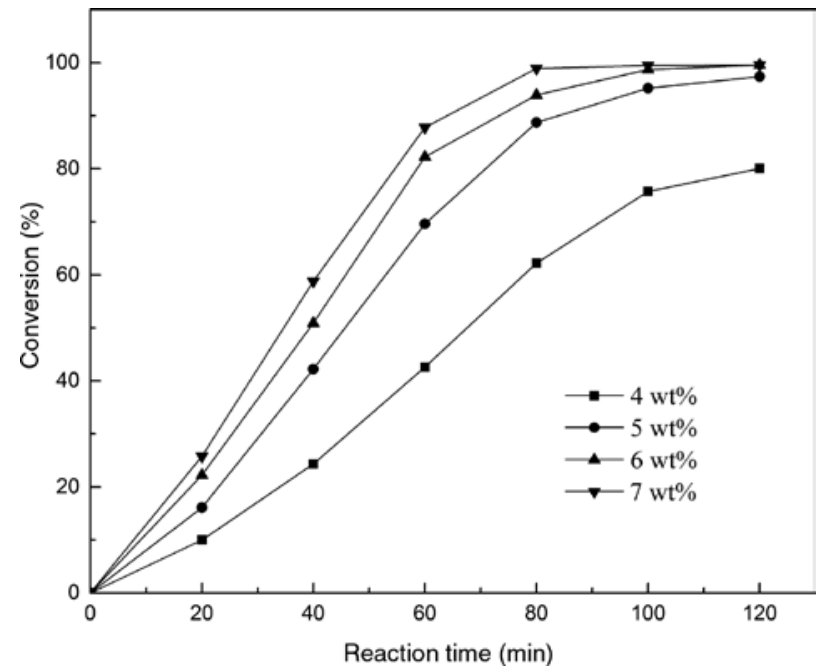

Figure 8: The effect of catalyst amount on transesterification of phospholipid (PC).

\subsection{Recyclability of catalyst}

The catalyst was reused in 10 consecutive cycles under optimal conditions, which included separation by filtration, washing with ethanol and drying under vacuum conditions. As seen in Figure 9, only 3\% decrease in PC conversion was observed after recycling three times. However, PC conversion dropped dramatically with increasin in the recycling. The structure change in recycled sodium silicate is shown in Figure 4. After recycling, the intensity of Si-O-Si stretching at $710 \mathrm{~cm}^{-1}$ decreased and the intensity of Si-O bending vibration at $1022 \mathrm{~cm}^{-1}$ and $\mathrm{Si}-\mathrm{O}$ stretching vibration at $958 \mathrm{~cm}^{-1}$ increased, which suggested that the Si-O-Si bond was broken. This characterization result was in agreement with that reported

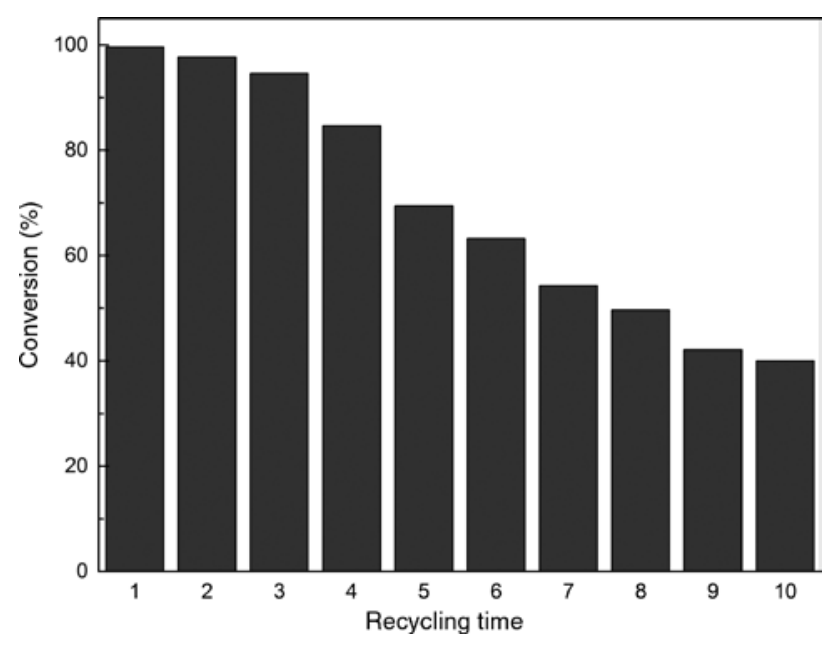

Figure 9: Recyclability of the calcined sodium silicate. 
Table 2: The sodium ion, strong base content of recycled catalyst and catalyst residue in filtrate.

\begin{tabular}{lrlr}
\hline Recycling & $\begin{array}{r}\mathrm{Na}^{+} \text {content } \\
\text { (\%) }\end{array}$ & $\begin{array}{l}\text { Catalyst residue } \\
\text { in filtrate }\end{array}$ & $\begin{array}{r}\text { Strong base } \\
\text { strength content }\end{array}$ \\
\hline 0 & 23.86 & $\mathrm{~A}$ & 1.61 \\
1 & 22.97 & $\mathrm{~A}$ & 1.54 \\
2 & 20.94 & $\mathrm{~A}$ & 1.42 \\
3 & 19.21 & $\mathrm{~A}$ & 1.34 \\
4 & 18.55 & $\mathrm{~A}$ & 1.25 \\
5 & 17.70 & $\mathrm{~A}$ & 1.14 \\
6 & 16.33 & $\mathrm{~A}$ & 1.03 \\
7 & 15.01 & $\mathrm{~A}$ & 0.88 \\
8 & 13.87 & $\mathrm{~A}$ & 0.71 \\
9 & 12.03 & $\mathrm{~A}$ & 0.54 \\
10 & 10.89 & $\mathrm{~A}$ & 0.35 \\
\hline
\end{tabular}

A: no catalyst residue.

in previous literature [21]. By contrast, the fresh, recycled catalyst and catalyst residue in reaction solution were analyzed by an ICP spectrometer. It can be seen in Table 2 that the sodium ion content decreased from $23.86 \%$ to $10.89 \%$ after recycling 10 times, which was due to the ionexchange between calcined sodium silicate and methanol [37]. In addition, the strong base content correspondingly decreased from $1.61 \mathrm{mmol} / \mathrm{g}$ to $0.35 \mathrm{mmol} / \mathrm{g}$. The decrease in catalyst activity was essentially attributed to the dissolution of sodium ion [38] and the decrease in strong base content. In addition, the ICP result also confirmed that the calcined sodium silicate could be separated completely by filtration, which was beneficial to the purification of GPC.

In view of all of the above results, the transesterification of PC proceeded rapidly with $6 \mathrm{wt} \%$ sodium silicate, $10.5 \mathrm{mmol} / \mathrm{l} \mathrm{PC}$ concentration and reaction temperature of $65^{\circ} \mathrm{C}$ for $120 \mathrm{~min}$ with stirring at $300 \mathrm{rpm}$. In addition, calcined sodium silicate could be completely separated by simple filtration and retained relatively high activity. Compared with the recently reported catalysts [10, 15], calcined sodium silicate had better catalytic activity in transesterification. In addition, the security of GPC and its application in food and medicine fields were not affected by calcined sodium silicate because of its non-toxicity and easy excretion from the human body. Although sodium ion dissolution was not avoided during the transesterification process, using sodium silicate as a catalyst could circumvent the drawback of toxic components or catalyst residue compared to the previously reported catalysts such as mercuric chloride [11], tetrabutylammonium hydroxide [12], and sodium methoxide [13]. Therefore, we believe that calcined sodium silicate has the potential to produce GPC in industry with a benign process.

\section{Conclusion}

Sodium silicate as an efficient and benign heterogeneous catalyst was successfully used in the production of GPC from natural lecithin. The maximum PC conversion of $99.5 \%$ could be obtained with 6 wt $\%$ sodium silicate, $10.5 \mathrm{mmol} / \mathrm{l} \mathrm{PC}$ concentration and reaction temperature of $65^{\circ} \mathrm{C}$ for $120 \mathrm{~min}$ with stirring at $300 \mathrm{rpm}$. Because of the characteristics of non-toxicity, easy excretion from the human body and complete separation from reaction mixture, using calcined sodium silicate as a catalyst did not affect the security and usage of GPC. Therefore, calcined sodium silicate could meet the demand of producing GPC with a benign process.

\section{References}

[1] Lorenzo DF, Fausto B, Guido C, Pietro M, Oreste P. EP. 0575717 1998.

[2] Yaqoob M, Nabi A, Hafeez I, Atif Ali S, Masoom-Yasinzai M. Anal. Lett. 1997, 30, 61-68.

[3] Dawsom RM, Mann T, White IG. Biochem. J. 1957, 65, 627-634.

[4] Amenta F, Franch F, Ricci A, Vega JA. Ann. N. Y. Acad. Sci. 1993 695, 311-313.

[5] Muratorio A, Bonuccelli U, Nuti A. Curr. Ther. Res. 1992, 52 , 741-752.

[6] Schmidt G, Thannhauser SJ. J. Biol. Chem. 1945, 161, 83-89.

[7] Puricelli L. EP. 04861001992.

[8] Puricelli L. EP. 05023571992.

[9] Song YS, Song ES, Kang DS, Song IW, Kang PG, Moon SC, Lee BG. WO. 1454762007.

[10] Li HY, Zhang XL, Bai WL, Zhang JB, Zhang TT, Zhao BX. React. Kinet. Mech. Catal. 2013, 108, 305-316.

[11] Mcarthur CS. US. 28648481958.

[12] Brockerhoff H, Yurkowski M. Can. J. Biochem. 1965, 43, 1777-1783.

[13] Giovanni T. EP. 0217765. 1990.

[14] Zhang TT, Zhang XL, Li HY, Bai WL, Zhao BX. React. Kinet. Mech. Catal. 2013, 110, 31-39.

[15] Li HY, Zhang XL, Zhang TT, Dou KK, Zhao BX. React. Kinet. Mech. Catal. 2012, 107, 345-354.

[16] Elmore AR. Int. J. Toxicol. 2005, 1, 103-117.

[17] Xie WL, Peng H, Chen LG. J. Mol. Catal. A Chem. 2006, 246, 24-32.

[18] Take Jl, Kikuchi N, Yoneda Y. J. Catal. 1971, 21, 164-170.

[19] Li BL, Wang J, Zhang XL, Zhao BX, Niu L. J. Agric. Food Chem. 2016, 64, 7555-7560.

[20] Fan FL, Jia LH, Guo XF, Lu XP, Chen J. Energy Fuels 2013, 17, 5215-5221.

[21] Guo F, Peng ZG, Dai JY, Xiu ZL. Fuel Process. Technol. 2010, 91, 322-328.

[22] Wang S, Hao PF, Li SX, Zhang AL, Guan YY, Zhang LN. Appl. Catal. A 2017, 542, 174-181.

[23] Tantirungrotechai J, Chotmongkolsap P, Pohmakotr M. Microporous Mesoporous Mater. 2010, 128, 41-47. 
[24] Halasz I, Agarwal M, Li R, Miller N. Catal. Lett. 2007, 117, 34-42.

[25] Ferraro JR, Manghnani MH. J. Appl. Phys. 1972, 44, 4595-4598.

[26] Masui H, Chen DP, Akai T, Yazawa T. Z. Naturforsch. 2002, 57, 473-478.

[27] Avhad MR, Sánchez M., Peńa E, Bouaid A, Martínez M, Aracil J, Marchetti JM. Fuel 2016, 179, 332-338.

[28] Liu XJ, Piao XL, Wang Y], Zhu SL. Energy Fuels 2008, 22, 1313-1317.

[29] Li H, Niu SL, Lu CM, Li J. Fuel 2016, 176, 63-71.

[30] Meher LC, Dharmagadda VSS, Naik SN. Bioresour. Technol. 2006, 97, 1392-1397.
[31] Balat M, Balat H. Appl. Energy 2010, 87, 1815-1835.

[32] Madhuvilakku R, Piraman S. Bioresour. Technol. 2013, 150, 55-59.

[33] Kodali DR, Tercyak A, Fahey DA, Small DM. Chem. Phys. Lipids 1990, 52, 163-170.

[34] Kalva A, Sivasankar T, Moholkar VS. Ind. Eng. Chem. Res. 2009, 48, 534544

[35] Gole VL, Gogate PR. Chem. Eng. Process. 2012, 53, 1-9.

[36] Korkut I, Bayramoglu M. Fuel 2016, 180, 624-629.

[37] Guo F, Wei NN, Xiu ZL, Fang Z. Fuel 2012, 93, 468-472.

[38] Long YD, Guo F, Fang Z, Tian XF, Jiang LQ, Zhang F. Bioresour. Technol. 2011, 102, 6884-6886. 